\title{
On the action of telephonic currents upon the galvanometer
}

\section{De Chardonnet}

To cite this article: M. De Chardonnet (1882) On the action of telephonic currents upon the galvanometer, Philosophical Magazine Series 5, 13:83, 468-468, DOI: $10.1080 / 14786448208627215$

To link to this article: http://dx.doi.org/10.1080/14786448208627215

曲 Published online: 28 Apr 2009.

Submit your article to this journal $₫$

Џ Article views: 2

Q View related articles $₫$ 
Once the ozone is liquefied in the capillary tube, it remains in that state long enough, even under the pressure of the atmosphere, for it to be examined either through the liquid ethylene or the refrigerated tube being withdrawn for a moment from that liquid. The deep-bJue liquid gradually diminishes in volume: the vaporization of the ozone is sufficiently slow, its diffusion sufficiently rapid, for the gas to appear colourless above the nearly black liquid; it is only at the moment when the last traces of the liquid disappear that one ascertains the production of an azure-blue gas. The vaporization of the liquid ozone would bring back the system to its initial state, if the ozone were not slowly decomposed by the mercury employed to compress the gases.-Comptes Rendus de l'Académic des Sciences, May 1, 1882, pp. 1249-1251.

\section{ON THE ACTION OF TELEPHONIC CURRENTS UPON THE GALVANOMETER. BY M. DE CHARDONNEI.}

If, in the telegraphic circuit, the receiver be replaced by a very sensitive galvanometer, and the trausmitter be influenced by means of a diapason, an organ-pipe, or the voice, no deflection is observed as long as the sound keeps the same intensity; but as soon as the sonorosity is increased or diminished, the needle is deflected : the direction of the deflection varies according to whether the amplitude of the vibrations of the sounding body is increasing or decreasing. The effect is more marked when the transmitter is shaken by a noise of short duration, such as a detonation, or by a body lightly tapped upon the vibratiug plate. In this last case the galvanometer-needle leaps like the seconds-hand of a clock. The experiment also succeeds very well when the sonnding body is briskly moved nearer to or away from the transmitter. These deflections appear, of course, much more distinctly when a microphone-transmitter, like Ader's, is employed; but they are visible with every kind of telephone.

The explanation appears very simple, at least for the whole of the facts collectively :-

As long as the oscillations of the vibrating plate retain the same amplitude, and consequently the same velocity, the currents induced alternately in the two directions at each complete vibration compensate each other's action upon the galvanometer, whether they emanate from an electromagnet or a microphone; but if the oscillations tend towards zero, for example, each odd semioscillation has more amplitude than the following even semioscillation, and the direct and the inverse indnced currents no longer put in motion the same quantities of electricity. The residues, of the same sign at each complete oscillation, accumulate so as to deflect the needle : and the more rapidly the sound diminishes, the greater is the deHection. This is what experiment demonstrates.-Comptes Renclus de l'Acarlémie des Sciences, March 27, 1882, t. xciv. p. 857. 